\title{
Erosion of SS41 Steel by Sand Blasting
}

\author{
C.-K. FANG and T.H. CHUANG \\ Erosion of SS41 steel by sand blasting, with abrasives of different particle sizes striking at different \\ angles, was experimentally investigated under different environmental conditions. Experiments were \\ conducted at temperatures of $25{ }^{\circ} \mathrm{C}, 35^{\circ} \mathrm{C}, 45{ }^{\circ} \mathrm{C}$, and $55^{\circ} \mathrm{C}$ and at $50,65,80$, and 95 pct relative \\ humidity (RH). The surface morphology of the eroded area was studied. In addition to the target \\ volume loss, the worn area and worn depths of the eroded material were investigated. Among the \\ test temperatures, it was found that the temperature of $45^{\circ} \mathrm{C}$ resulted in the lowest volume loss and \\ worn area, but also in the deepest worn scar at nearly every attack angle. Among the test humidity \\ conditions, the deepest worn scar occurred at a low attack angle (15 deg) for very low and high \\ humidity conditions ( $\mathrm{RH}=50$ and $95 \mathrm{pct}$ ), while it occurred at intermediate angles for intermediate \\ humidity conditions ( $\mathrm{RH}=65$ and $80 \mathrm{pct}$ ). If the applied pressure of the carrier gas and the total \\ weight of the particles were constant, finer particles tended to result in more volume loss and deeper \\ worn scars, with only a minor effect on the worn area.
}

\section{INTRODUCTION}

STRUCTURAL steels are often used in outdoor or harsh conditions, in which the synergy of wind and sand or dust may result in erosion of the materials. The difference in environmental variables such as temperature and humidity might result in varying degrees of erosion damage. A determination of the effect of environmental variables on erosion damage is, thus, essential in estimating the lifetime of the materials. The previous studies of erosion behavior were concentrated mainly on the effects of impingement angle and velocity, microstructures and mechanical behaviors, particle size and shape, erosion mechanisms, and its modeling. Little research ${ }^{[1,2]}$ has been done on the effect of temperature on erosion damage, while research on the influence of humidity on erosion could hardly be found in the literature. In an article by Smeltzer's et al. ${ }^{[1]}$ the erosion behaviors of Ti6Al-4V, 17-7 PH, 410 stainless steel, and $2024 \mathrm{Al}$ at room temperature, $204{ }^{\circ} \mathrm{C}$, and $371{ }^{\circ} \mathrm{C}$ were studied. They found that erosion losses were reduced with increasing temperatures. This is contrary to our expectation, since the flow strengths and energies required to remove a target material decrease with increasing temperature. Gat and Tabakoff ${ }^{[2]}$ studied the erosion of different materials from $10{ }^{\circ} \mathrm{C}$ to 204 ${ }^{\circ} \mathrm{C}$. Their investigation indicated that erosion damage may increase or decrease as the temperature increases, depending upon the attack angle and upon the test temperature with respect to the thermal properties of the material.

The effect of particle size and shape on erosion has been widely studied. ${ }^{[1,3-6]}$ However, the effect of particle size on erosion might depend on environmental conditions, viz., temperature and $\mathrm{RH}$. One of the objectives of the present work is to investigate the particle-size effect in different environmental conditions.

The steel JIS SS41 has been widely used for general

C.-K. FANG, Associate Professor, is with the Department of Mechanical Engineering, China Institute of Technology and Commerce, Taipei, Taiwan 11522, Republic of China. T.H. CHUANG, Professor, is with the Institute of Materials Science and Engineering, National Taiwan University, Taipei, Taiwan 106, Republic of China.

Manuscript submitted April 15, 1998. structures. Damage caused by the blasting of wind and sand is a common problem. The aim of the present research is to study the effect of temperature and humidity on erosion damage of SS41, a rolled structural steel. In addition to the target volume loss, the worn area and worn depth are investigated at different temperatures $\left(25^{\circ} \mathrm{C}, 35^{\circ} \mathrm{C}, 45^{\circ} \mathrm{C}\right.$, and $55^{\circ} \mathrm{C}$ ) and in different $\mathrm{RH}$ conditions $(50,65,80$, and 95 pct). Finally, the effects of particle size and the morphologies of the eroded surfaces are investigated as well.

\section{EXPERIMENTAL}

A sand blast-type test rig with a gas jet based on ASTM G76 was employed in the erosion tests. The setup consists of a particle-gas supply system, an exit nozzle, and a chamber. The chamber is $1000 \times 800 \times 500 \mathrm{~mm}$ in size, which enables specimens to be held under well-controlled exposure conditions of $0{ }^{\circ} \mathrm{C}$ to $65{ }^{\circ} \mathrm{C}\left( \pm 2{ }^{\circ} \mathrm{C}\right)$ in temperature and 20 to $98 \mathrm{pct}( \pm 3 \mathrm{pct}) \mathrm{RH}$. Compressed air with a pressure of $414 \mathrm{kPa}$ (60 psi) was used to accelerate abrasive particles. The quality (temperature and moisture) of the compressed air is the same as that in the chamber. The air is mixed with the abrasive particles from the reservoir and flows into the nozzle. The flow rate can be controlled in the range from 10 to $100 \mathrm{~L} / \mathrm{mi}$. The working distance (between the specimen and nozzle tube) is $20 \mathrm{~mm}$. Each specimen was attached to a fixture, which can be rotated to change the orientation of the specimen relative to the impinging stream. Erosion tests were conducted at different attack angles, viz., 15, 30, 45, 60, 75, and $90 \mathrm{deg}$.

A commercial-grade JIS SS41 steel was cut into specimens with dimensions of $50 \times 45 \times 3 \mathrm{~mm}$. The as-received surface, with an initial surface roughness $\left(R_{a}\right)$ of $0.91 \mu \mathrm{m}$, was directly employed for testing after ultrasonic rinsing in acetone. After weighing, each specimen was conditioned in the constant temperature-constant humidity chamber for 24 hours prior to testing. It is noted that normal ambient atmospheric conditions $\left(18{ }^{\circ} \mathrm{C}\right.$ to $\left.28{ }^{\circ} \mathrm{C}\right)$ and dry test gas are specified in ASTM G76. In order to investigate the environmental effects, erosion tests in the present study were performed at temperatures of $25{ }^{\circ} \mathrm{C}, 35^{\circ} \mathrm{C}, 45^{\circ} \mathrm{C}$, and $55^{\circ} \mathrm{C}$ and at 50,65, 80, and 95 pct RH. Three samples have been 


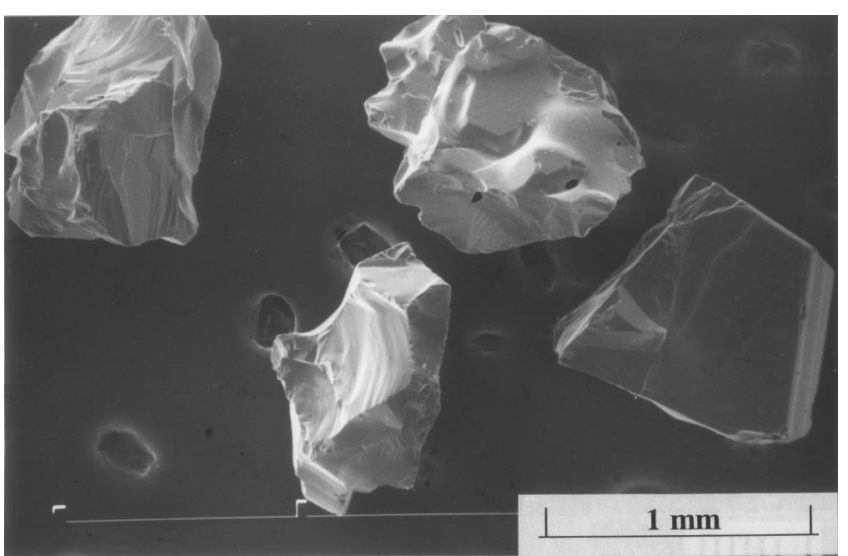

(a)

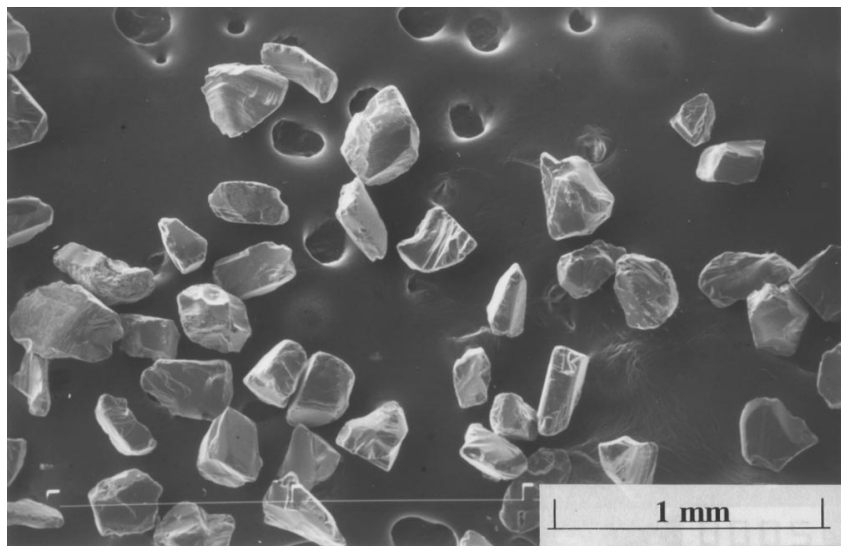

(b)

Fig. 1-Scanning electron micrographs of abrasive particles of grit sizes (a) 24 and (b) 80

made using one parameter set for averaging. The standard variations are less than 5 pct. Silicon carbide $(\mathrm{SiC})$ abrasive particles of 24- and 80-grit sizes, with uniform particle size, moisture, and chemical composition, were employed as the erodent material, as shown in Figures 1(a) and (b), respectively. In each test, the specimen was exposed to a total of $2.5 \mathrm{~kg}$ abrasive for 12 minutes in the case of $\mathrm{SiC} 24$, or for 15 minutes in the case of SiC 80. After sand blasting, each specimen was brushed off lightly and weighed to determine the weight loss due to erosion, which was then converted to a volume loss. The worn area was measured using a square grid pattern. The area for each square grid was 1 $\mathrm{mm}^{2}$. Dividing the volume loss by the worn area, the mean value of the worn depth was obtained. Surface morphologies of the eroded surfaces were analyzed through scanning electron micrography (SEM).

\section{RESULTS AND DISCUSSION}

\section{A. Surface Morphologies}

The SEM micrographs of the eroded surfaces after sand blasting, for SS41 steel, are shown in Figure 2. The specimens were eroded at room temperature and in 80 pct RH. $\mathrm{SiC}$ particles of a 24-grit size were used as the erodent. The results for 15 to 90 deg attack angles are illustrated in Figures 2(a) through (f). Extensive microploughing is evident for low attack angles, while it is not observed for frontal impact, as shown in Figure 2(f). The direction of ploughing in surface morphologies coincides with the direction of particle motion during sand blasting, which is from the bottom to the top on the micrographs. Microcracking and chipping can be observed.

\section{B. The Effect of Temperature}

Figure 3 illustrates the effects of temperature on erosion damage by 80 -grit $\mathrm{SiC}$ particles at different attack angles. The testing temperatures were $25{ }^{\circ} \mathrm{C}, 35^{\circ} \mathrm{C}, 45^{\circ} \mathrm{C}$, and 55 ${ }^{\circ} \mathrm{C}$, while the $\mathrm{RH}$ was kept at 80 pct. The results for target volume loss, worn area, and worn depths are depicted in Figures 3(a) through (c), respectively.

Referring to the pattern revealed in Figure 3(a), the attack angle has only a minor effect on the volume loss. Comparing the curves for room temperature and $35{ }^{\circ} \mathrm{C}$, a negligible difference is observed in the volume loss. At a higher temperature, the volume removal is significantly reduced at $45^{\circ} \mathrm{C}$. However, the volume loss is increased if the temperature is further increased, as indicated by the curve corresponding to $55^{\circ} \mathrm{C}$. As a result, the least volume loss occurs at $45^{\circ} \mathrm{C}$ for any attack angle.

The worn area was investigated as well. The worn region is circular in shape for frontal impact, while it is elliptical for attack angles less than $90 \mathrm{deg}$. It was observed that the major axis of the ellipse increases with decreasing attack angle $(\theta)$ and is approximately proportional to $1 / \sin \theta$ when $\theta \geqq 45 \mathrm{deg}$. For $\theta \leqq 45 \mathrm{deg}$, the proportional factor becomes less than $1 / \sin \theta$. On the other hand, the minor axis of the ellipse decreases with a decreasing attack angle. This might be due to the fact that the particles spread out in all directions after hitting the target for near-front impact (a larger $\theta$ ), while the particles tend to flow in a consistent direction after rebounding if the specimens are inclined (a smaller $\theta$ ). Because of the increase in the major axis and decrease in the minor axis for a decreasing $\theta$, the resulting worn area is not significantly related to attack angle, as illustrated in Figure 3(b). Figure 3(b) also shows the effects of temperature on the worn area. Obviously, a $45{ }^{\circ} \mathrm{C}$ temperature results in the smallest worn area, while the largest area occurs at 55 ${ }^{\circ} \mathrm{C}$ at nearly every attack angle.

Dividing the values of volume loss (in Figure 3(a)) by those of the worn areas (in Figure 3(b)), the results for the mean worn depth are depicted in Figure 3(c). It is found that a temperature of $45^{\circ} \mathrm{C}$ results in the deepest worn scars at most of the attack angles. Although the temperature of $45{ }^{\circ} \mathrm{C}$ results in the least volume removal (Figure 3(a)), the worn region is in a very small area (Figure 3(b)), thus resulting in a deep worn scar. On the other hand, the shallowest worn scar occurs at $55^{\circ} \mathrm{C}$ at any attack angle. The curves for $25^{\circ} \mathrm{C}$ and $35^{\circ} \mathrm{C}$ fall in between those for $45^{\circ} \mathrm{C}$ and $55^{\circ} \mathrm{C}$.

\section{The Effect of Humidity}

Referring to Figure 4, we now examine the influence of humidity on erosion at different attack angles. Erosion tests were conducted at room temperature and under different humidity conditions, viz., RH of 50, 65, 80, and 95 pct. SiC particles of an 80-grit size were used as an abrasive.

Figure 4(a) shows the variation of volume loss with attack 

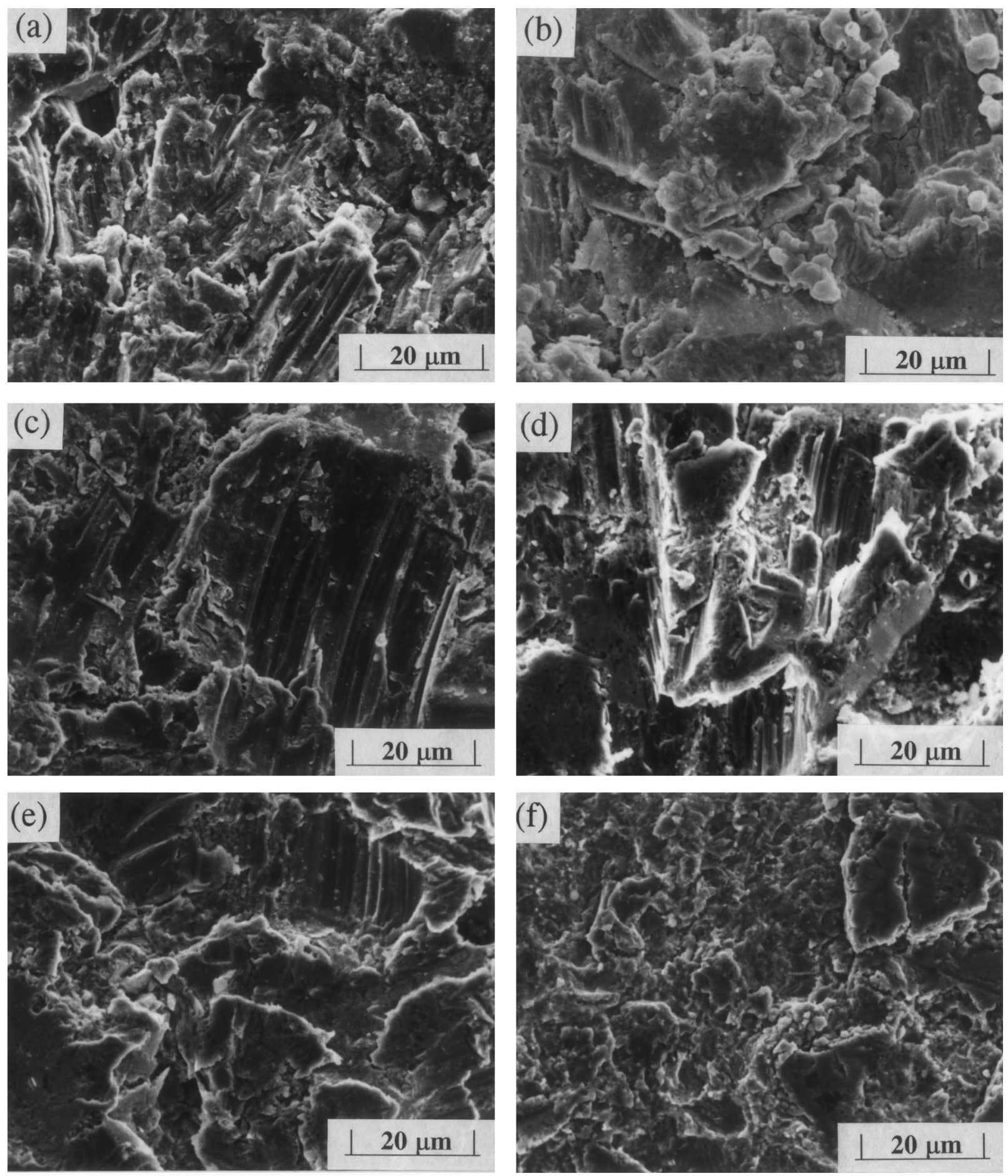

Fig. 2-Surface morphologies of SS41 steel eroded by SiC particles of grit size 24 at $(a) 15 \mathrm{deg},(b) 30 \mathrm{deg},(c) 45 \mathrm{deg},(d) 60 \mathrm{deg},(e) 75 \mathrm{deg}$, and $(f)$ 90 deg attack angles.

angle. The peak attack angles for volume removal are 45 , 35,45 , and 45 deg at 50,65, 80, and 95 pct RH, respectively. The effect of humidity on the peak attack angle for volume loss is minor. From the four curves in Figure 4(a), it is found that the volume loss for an RH of 80 pct is significantly larger than that for the other humidity conditions at all attack angles.

The variation of worn area with attack angles under different humidity conditions is depicted in Figure 4(b). It is found that the worn area increases with the increase in $\mathrm{RH}$ for an
RH $\leqq 80$ pct. However, the worn area drops back to a low level (to that for an RH of $50 \mathrm{pct}$ ) if the RH is extremely high (95 pct). Similar to the results for volume loss (Figure 4(a)), the worn area for an RH of 80 pct attains the highest value compared to the other humidity conditions at all attack angles.

Figure 4(c) demonstrates the worn depth $v s$ attack angle. From the curves for different humidity conditions, we observed that the peak attack angle for worn depth is 45 deg for an RH of 65 and 80 pct. However, the deepest worn 


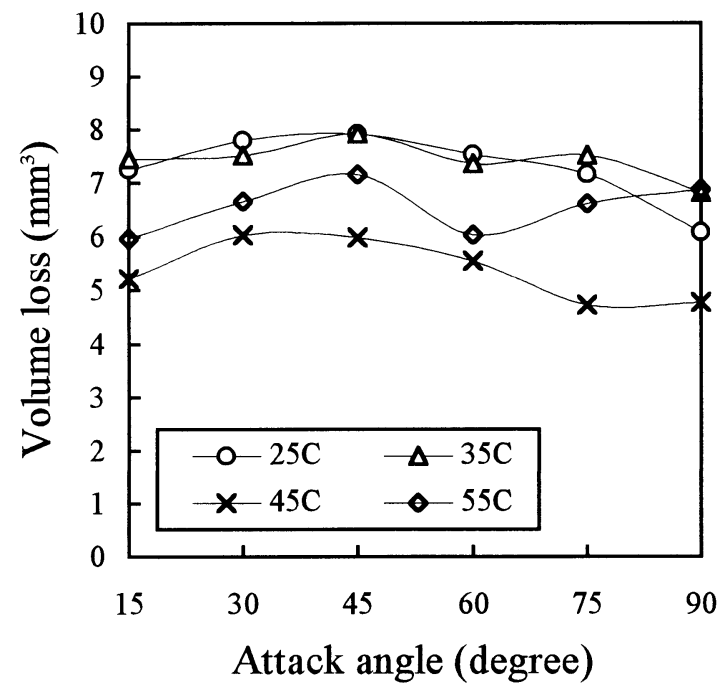

(a)

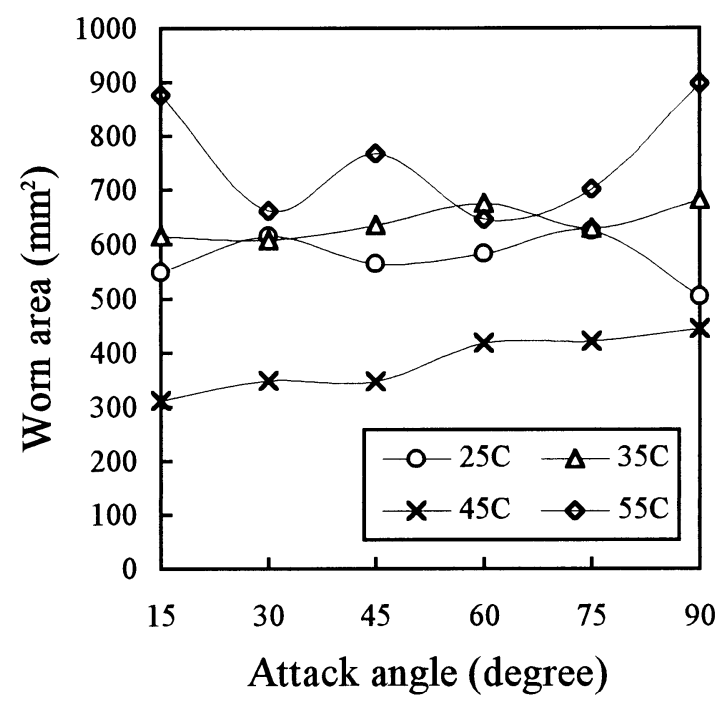

(b)

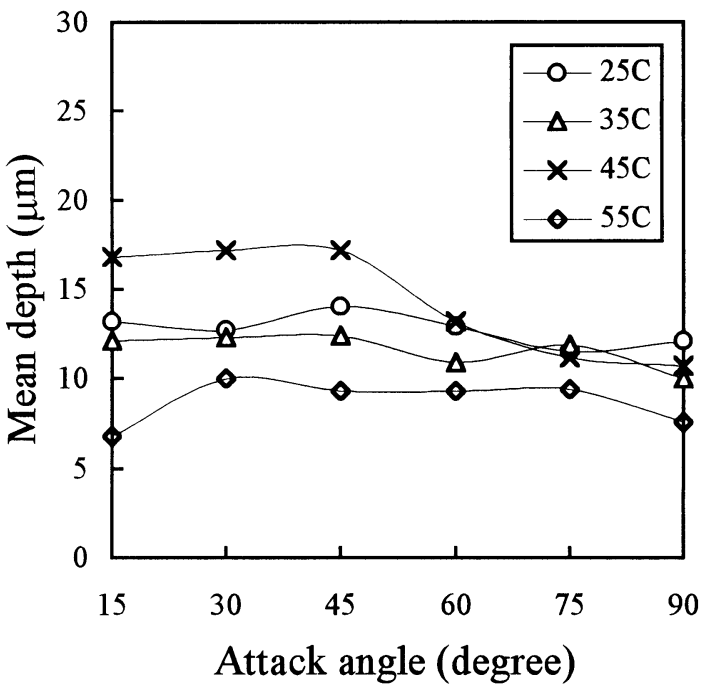

(c)

Fig. 3-Effects of temperature on erosion damage: (a) volume loss, $(b)$ worn area, and $(c)$ worn depth.

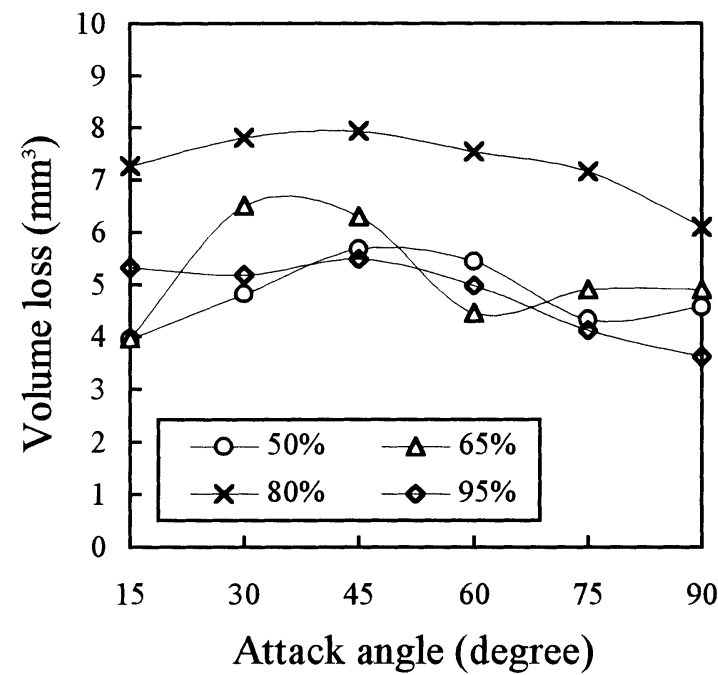

(a)

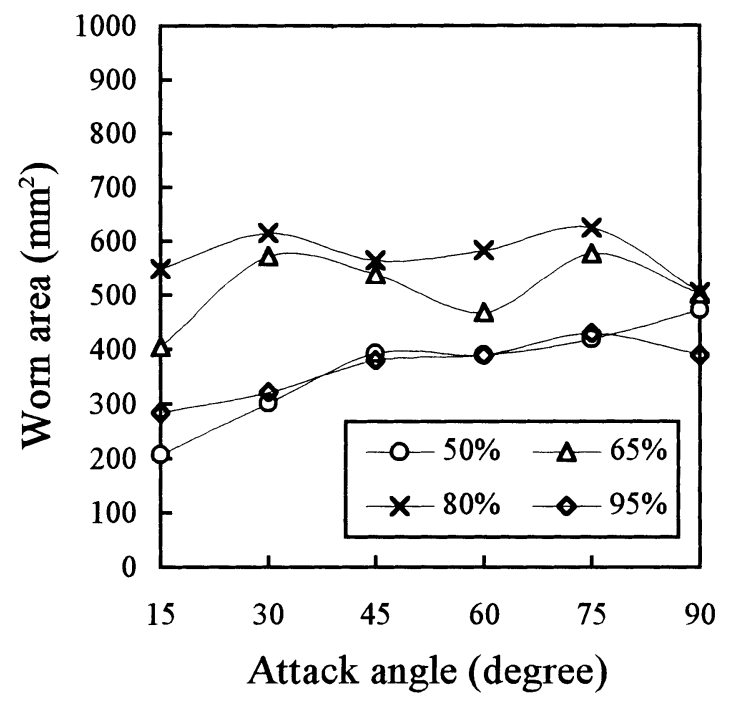

(b)

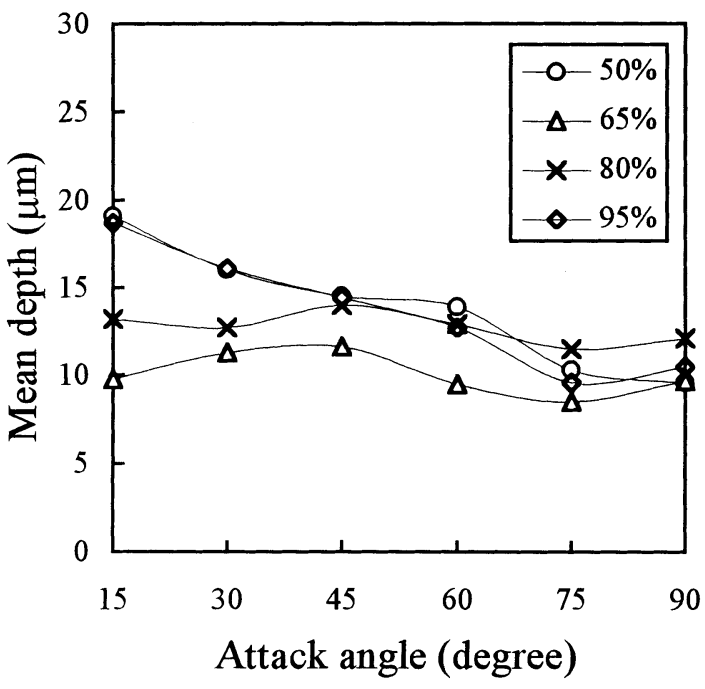

(c)

Fig. 4-Effects of relative humidity on erosion damage: (a) volume loss, (b) worn area, and (c) worn depth. 


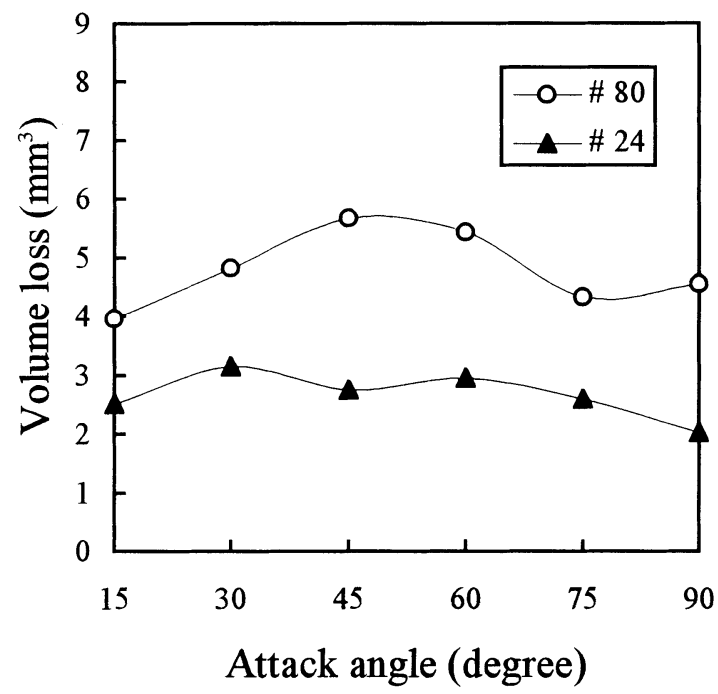

(a) R.H. $=50 \%$

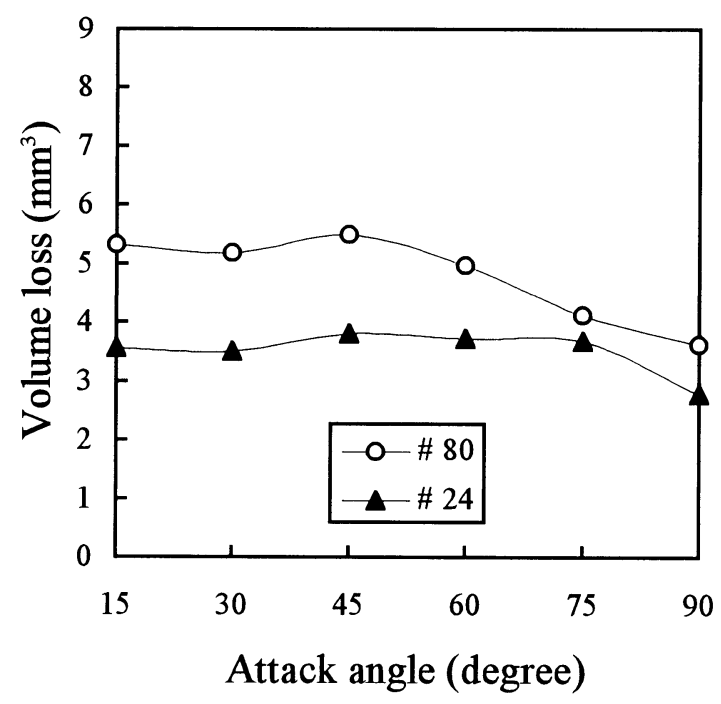

(b) R.H. $=95 \%$

Fig. 5- $(a)$ and (b) Effects of eroding particle size on the volume loss (at room temperature).

scar occurs at a low attack angle (15 deg) for low and high humidity conditions (an RH of 50 and 95 pct). Among the test humidity conditions, an RH of 65 pct attains the lowest value of worn depth at any attack angle, as indicated by the lowest curve in Figure 4(c).

\section{Effects of Particle Size in Different Environments}

The effects of particle size on erosion under different environmental conditions are illustrated in Figures 5 through 10 , where \#80 and \#24 in the legend represent the grit sizes of the abrasive particles. The applied pressure of the carrier gas and the total weight of the abrasive in each test are constant. Figures 5 and 6 show the results for volume loss. The results for room temperature are illustrated in Figure 5. It is obvious that fine particles (80-grit size) yield more volume loss than coarse particles (24-grit size). A similar trend is observed in Figure 6, where the $\mathrm{RH}=80$ pct.

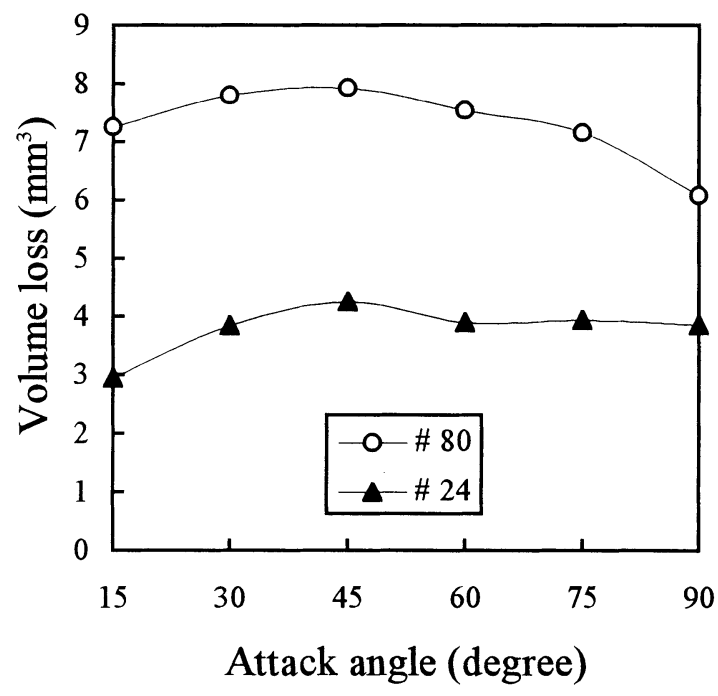

(a) $25^{\circ} \mathrm{C}$

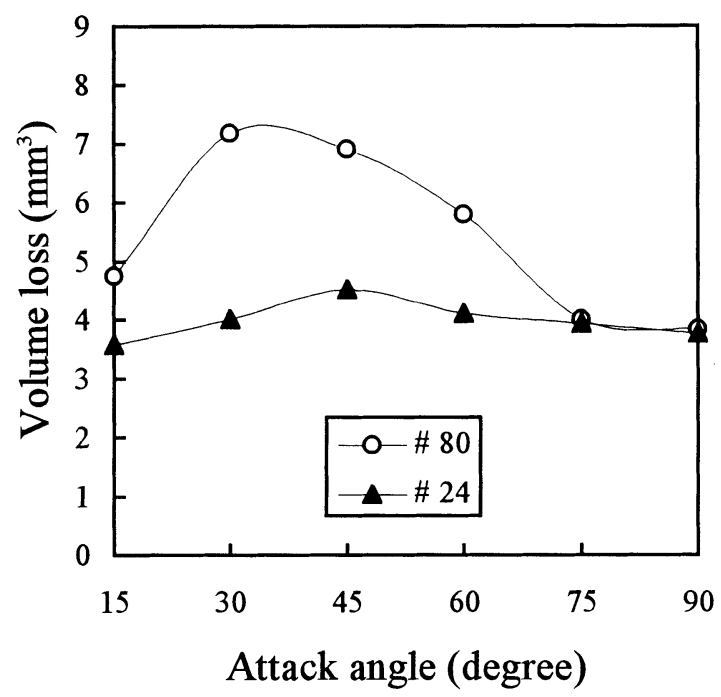

(b) $45^{\circ} \mathrm{C}$

Fig. 6- (a) and (b) Effects of eroding particle size on the volume loss $(\mathrm{RH}=80$ pct $)$.

Particularly, such a particle size effect is very significant at an $\mathrm{RH}$ of 80 pct and a temperature $(T)$ of $25^{\circ} \mathrm{C}$, as shown in Figure 6(a).

According to the study by Goodwin et al. ${ }^{[3]}$ of ductile materials, an increase in particle size increases the erosion damage until a saturation level is reached, after which no further change is indicated. Yerramareddy and Bahadur ${ }^{[6]}$ stated that the erosion rate $R=\varepsilon / M$ ( $\varepsilon$ and $M$ being the erosion mass loss and the total mass of the erodents, respectively) is independent of the particle size for the cutting mode. On the other hand, $R$ is proportional to $d^{2 / 3}$ ( $d$ being the particle diameter) for the deformation mode. Smeltzer et al. ${ }^{[1]}$ demonstrated that erosion volume loss per particle varies linearly with particle volume and mass, at constant velocity, through the particle size range from 20 to 175 $\mu \mathrm{m}$. Descriptions of the particle-size effect seem to vary individually in the literature. Therefore, it is necessary to clarify the relationship between erosion and particle size. 


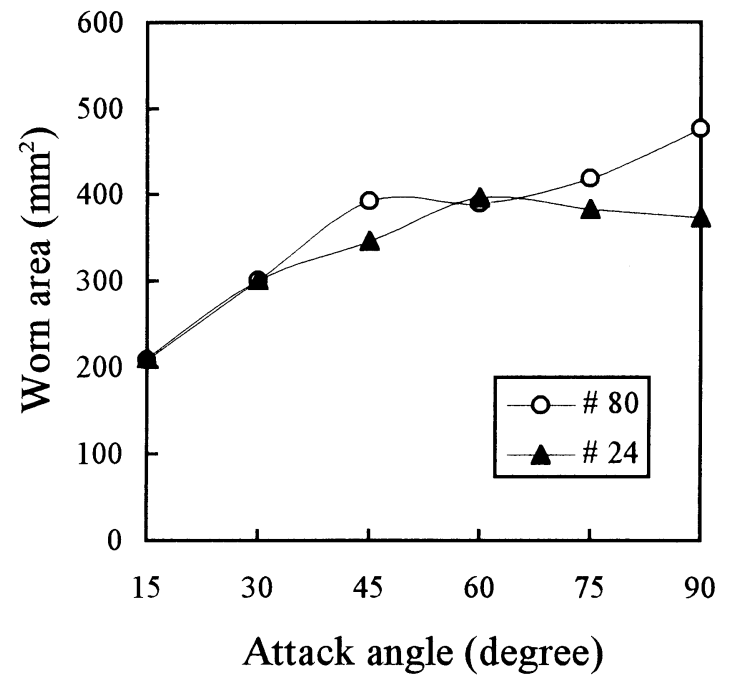

(a) R.H. $=50 \%$

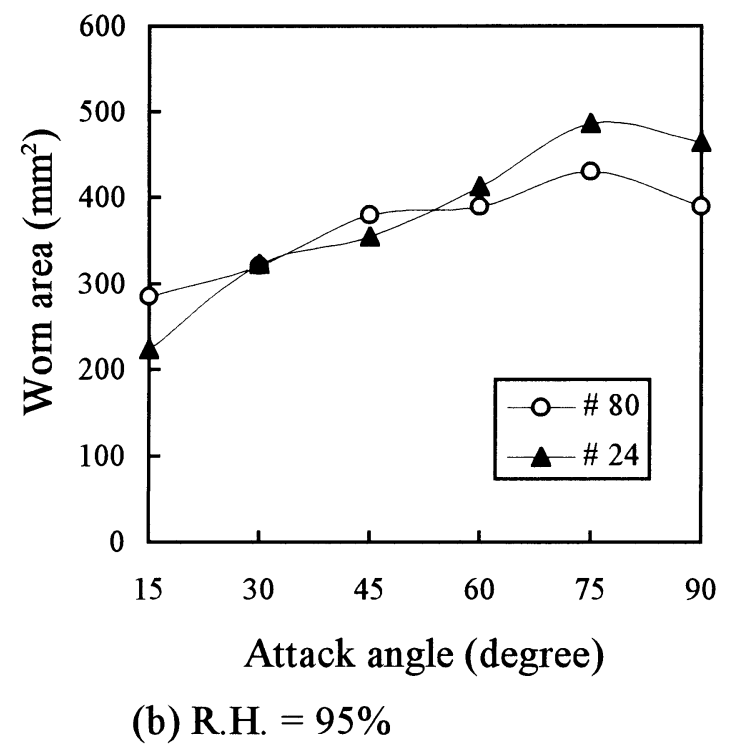

Fig. 7-(a) and (b) Effects of eroding particle size on the worn area (at room temperature).

According to the cutting model of erosion developed by Finnie, ${ }^{[7]}$ the erosive mass loss $\varepsilon=K\left(M v^{2} / 2\right) f(\alpha)$, where $K$ is a material constant, $v$ is the impact velocity, and $f(\alpha)$ is a function of the attack angle $\alpha$. This equation was used to explain the results of Goodwin et al. ${ }^{[3]}$ and Yerramareddy and Bahadur. ${ }^{[6]}$ It can be alternatively written as $\varepsilon / N=$ $K\left(m v^{2} / 2\right) f(\alpha)$, where $N$ is the total number of particles, and $m$ is the mass of the individual particle. Consequently, the erosion mass per particle $(\varepsilon / N)$ is proportional to the particle mass, consistent with the results of Smeltzer et al. ${ }^{[1]}$ if the cutting model dominates. As a result, the cutting model by Finnie can explain part of the results in the three aforementioned articles.

Yerramareddy and Bahadur ${ }^{[6]}$ indicated that cutting is the dominant mechanism for particles larger than $50 \mu \mathrm{m}$, which is the critical diameter $\left(d_{c}\right)$ for mode transition from deformation to cutting. It needs to be pointed out that the value of $d_{c}$ depends on the target material and attack angle. According to the eroded morphologies of the targets in the present

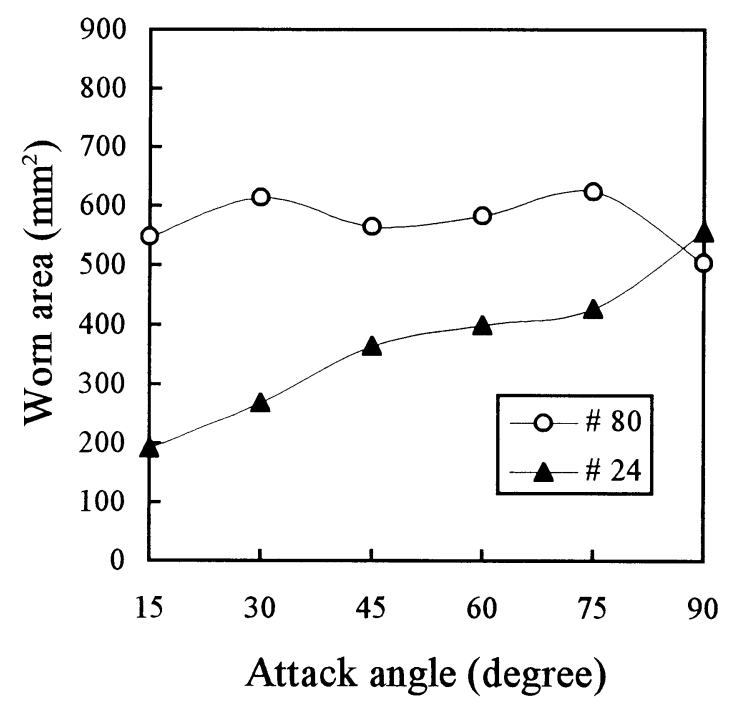

(a) $25^{\circ} \mathrm{C}$

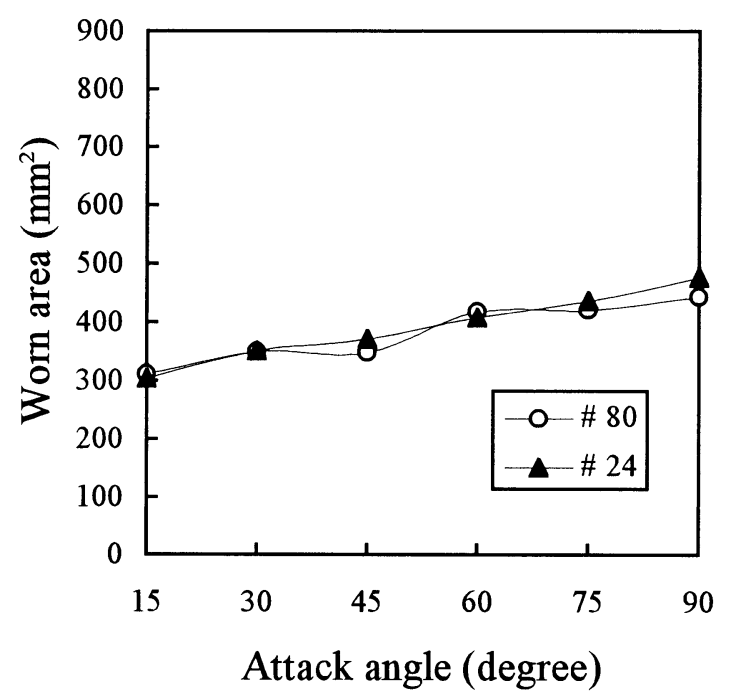

(b) $45^{\circ} \mathrm{C}$

Fig. 8- $(a)$ and $(b)$ Effects of eroding particle size on the worn area $(\mathrm{RH}=$ $80 \mathrm{pct})$.

research, the cutting mode is dominant for low and intermediate attack angles. According to the postulation of Yerramareddy and Bahadur, the erosion rate should not depend on the particle size in the cutting mode. This seems to contradict our observation. However, the postulations in the three aforementioned articles were based upon the assumption of a constant impact velocity. In reality, the impact velocity depends on the particle size. Consequently, the pressure of the carrier gas was kept constant in the present research. The cutting model of Finnie ${ }^{[7]}$ can be alternatively written as $\varepsilon=K N E_{k} f(\alpha)$, where $E_{k}$ is the mean kinetic energy of the particle immediately before impact. We note that the kinetic energy is due to the gravity $(\mathrm{mg})$ of the particles and the pressure $(p)$ of the carrier gas. If the small gap between the tube and the specimen surface is negligible, $E_{k}=(p A+m g) h$, where $A$ is the cross-sectional area of the individual particle, and $h$ is the length of the acceleration tube. Consequently, $\varepsilon=K(M / m)(p A+m g) h f(\alpha)$, or $\varepsilon=$ 


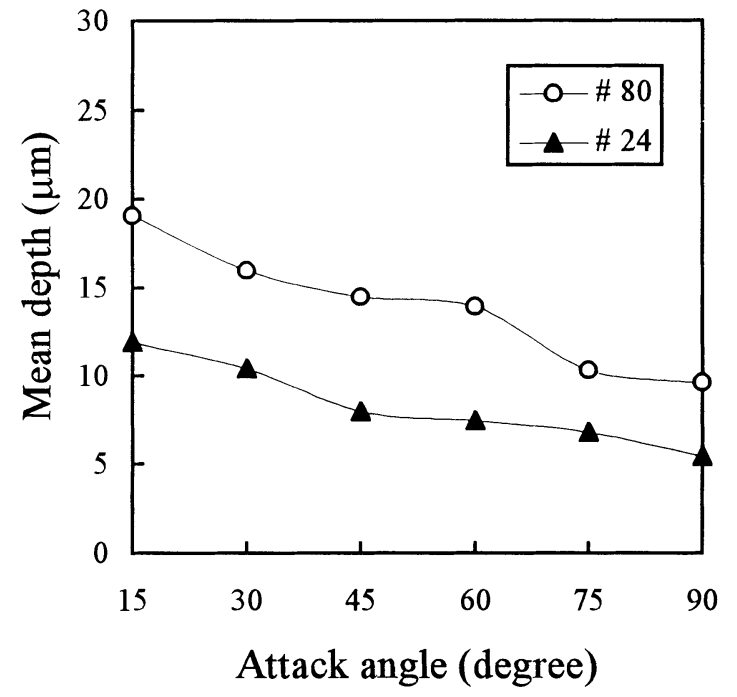

(a) R.H. $=50 \%$

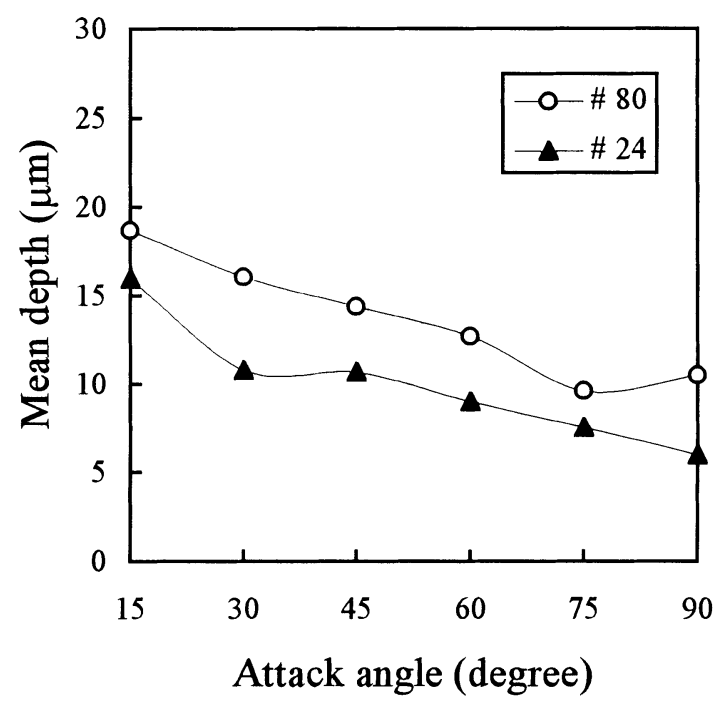

(b) R.H. $=95 \%$

Fig. 9-(a) and (b) Effects of eroding particle size on the worn depth (at room temperature).

$K M[p(A / m)+g] h f(\alpha)$, alternatively. We also note that $A=$ $k_{1} \pi d^{2} / 4$ and $m=D_{p} k_{2} \pi d^{3} / 6$, where $D_{p}$ is the density of the particles, and $k_{1}$ and $k_{2}$ are constants depending on the geometry of the erodents $\left(k_{1}=k_{2}=1\right.$ for a spherical particle). The erosion rate is

$$
R=K\left[\left(3 k p / 2 d D_{p}\right)+g\right] h f(\alpha)
$$

where $k=k_{1} / k_{2}$. Consequently, the erosion rate increases with a decrease in particle size. The previous equation can be alternatively written as $V_{t}=K M\left[\left(3 k p / 2 d D_{p}\right)+g\right] h f(\alpha) /$ $D_{t}$, where $D_{t}$ and $V_{t}$ are the density and volume loss of the target, respectively. As a result, the erosive volume loss increases with the decrease in particle diameter if the total mass of the particles is fixed. The previous equation is, thus, qualitatively consistent with our experimental results.

On the basis of the aforementioned articles ${ }^{[1,3,6]}$ and the present study, we can make conclusions regarding the particle-size effect on erosion rate. At a constant impact velocity,

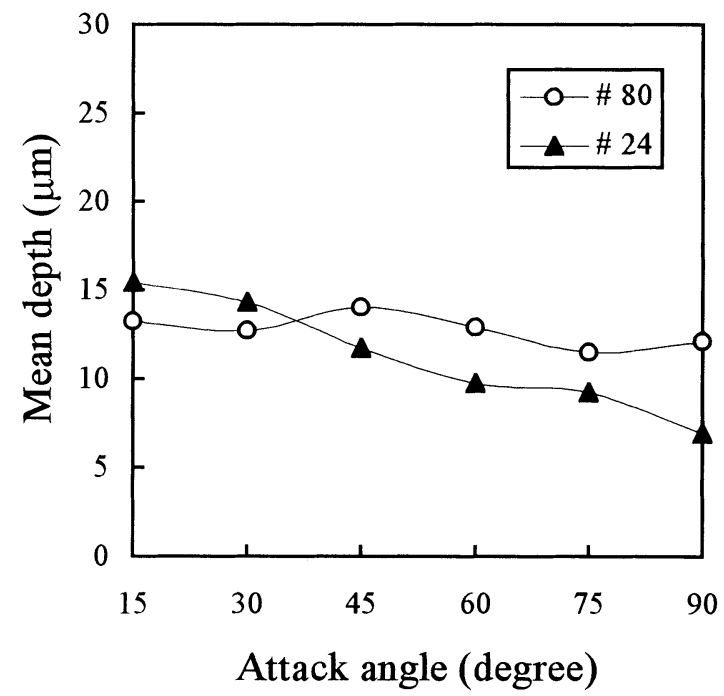

(a) $25^{\circ} \mathrm{C}$

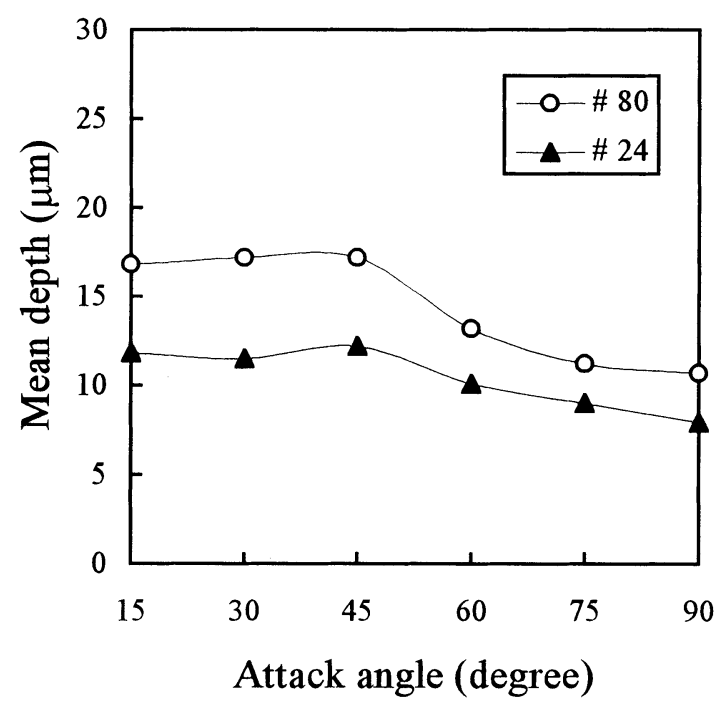

(b) $45^{\circ} \mathrm{C}$

Fig. 10- $(a)$ and $(b)$ Effects of eroding particle size on the worn depth $(\mathrm{RH}=80 \mathrm{pct})$.

the erosion rate is independent of the particle size for the cutting mode $\left(d>d_{c}\right)$, while $R$ is proportional to $d^{2 / 3}$ for the deformation mode $\left(d<d_{c}\right)$. However, the erosion loss per particle varies linearly with particle size for the cutting mode. On the other hand, if the applied pressure of the carrier gas is fixed, the erosion rate increases with the decrease in particle size.

Figures 7 and 8 illustrate the results of worn area $v s$ attack angle for different particle sizes. In general, a larger attack angle tends to result in a larger worn area. The particle size has only a minor effect on the worn area. The result for room temperature and an $\mathrm{RH}$ of 80 pct is an exception, where the worn areas for fine particles are considerably larger than those for coarse ones at most of the attack angles.

The results for the worn depth are depicted in Figures 9 and 10. In contrast to that for worn area, a higher attack angle tends to result in less worn depth. It is found that 
fine abrasive particles tend to cause deeper craters than coarse particles.

\section{CONCLUSIONS}

1. Extensive microploughing is evident for low attack angles, while it is not observed for frontal impact.

2. In the temperature range from $25^{\circ} \mathrm{C}$ to $55^{\circ} \mathrm{C}$, a temperature of $45^{\circ} \mathrm{C}$ results in the least volume loss and worn area, but the deepest worn scar at almost any attack angle.

3. The temperature has only a minor effect on the peak attack angle.

4. The effect of humidity on the peak attack angle for volume loss is minor. On the other hand, the effect of humidity on the peak attack angle for worn depth is unusual. The deepest worn scar occurs at a low attack angle (15 $\mathrm{deg}$ ) for very low and high humidity conditions (RH of
50 and 95 pct), while it occurs at intermediate angles for intermediate humidity conditions (RH of 65 and $80 \mathrm{pct}$ ).

5. In general, finer particles tend to result in more volume loss and a deeper worn scar, with only a minor effect on worn area, if the applied pressure of the carrier gas and total weight of the particles are constant.

\section{REFERENCES}

1. C.E. Smeltzer, M.E. Gulden, and W.A. Compton: J. Basic Eng., 1970, vol. 92 , pp. 639-54.

2. N. Gat and W. Tabakoff: Wear, 1978, vol. 50, pp. 85-94.

3. J.E. Goodwin, W. Sage, and G.P. Tilly: J. Basic Eng., 1970, vol. 92, pp. 619-26.

4. R.E. Winter and I.M. Hutchings: Wear, 1974, vol. 29, pp. 181-94.

5. S. Bahadur and R. Badruddin: in Wear of Materials, K.C. Ludema, ed., ASME, New York, NY, 1989, pp. 143-53.

6. S. Yerramareddy and S. Bahadur: Wear, 1991, vol. 142, pp. 253-63.

7. I. Finnie: Wear, 1960, vol. 3, pp. 87-103. 